\title{
Critério de seleção indireta para a produtividade de grãos em feijão
}

\author{
Indirect selection strategy to grain yield in common bean
}

\author{
Nerinéia Dalfollo Ribeiro ${ }^{I *}$ Alberto Cargnelutti Filho' ${ }^{I}$ Nerison Luís Poersch ${ }^{\mathrm{II}}$ \\ Daniele Piano Rosa ${ }^{\text {III }}$
}

\begin{abstract}
Com o objetivo de avaliar a associação linear entre a nota geral de adaptação e a produtividade de grãos de feijão como critério para a seleção indireta, foram conduzidos nove experimentos durante os anos de 2000/2001 a 2004/ 2005, em duas épocas de cultivo, no Estado do Rio Grande do

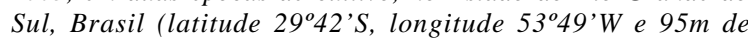
altitude). A nota geral de adaptação, avaliada por uma escala de notas (1: excelente a 9: péssimo), e a produtividade de grãos foram determinadas em 14 cultivares de feijão. Correlação linear negativa foi verificada entre a nota geral de adaptação e a produtividade de grãos $(r=-0,6134)$. A seleção indireta, por meio da nota geral de adaptação, é eficiente para o incremento da produtividade de grãos de feijão em linhas endogâmicas.
\end{abstract}

Palavras-chave: Phaseolus vulgaris L., linhas endogâmicas, análise de correlação.

\section{ABSTRACT}

The objective of this research was to investigate the correlation between general adaptation note and grain yield as indirect selection strategy. Nine experiments were conducted in the agricultural years of 2000/2001 and 2004/ 2005, in two growing seasons, at Rio Grande do Sul State, Brazil (latitude $29^{\circ} 42^{\prime}$ S, longitude $53^{\circ} 49^{\prime} \mathrm{W}$ and altitude $95 \mathrm{~m}$ ). The general adaptation note was evaluated for the grade scale, where 1 was = excellent and 9 was = very bad, and grain yield was determinate in 14 common bean cultivars. Negative linear correlation was obtained between the general adaptation note and grain yield $(r=-0.6134)$. The indirect selection for the general adaptation note is efficient for increment grain yield in common bean in inbred lines.
Key words: Phaseolus vulgaris L., inbred lines, correlation analysis.

O melhoramento genético do feijão (Phaseolus vulgaris L.) tem priorizado o aumento da produtividade de grãos, e ganho genético médio de 38,59kg ha-1 ano-1 $^{-1}$ foi observado no Estado do Rio Grande do Sul, no período de 1998 a 2005 (RIBEIRO et al., 2008). O Método Genealógico tem sido muito utilizado para o desenvolvimento de cultivares de feijão. Nesse método, a seleção é iniciada em gerações precoces, entre e dentro de famílias, com base na identificação visual de plantas com caracteres superiores, o que requer habilidade do melhorista.

A seleção precoce apresenta baixa eficiência em feijão (HAMBLIN \& EVANS, 1976; PATIÑO \& SINGH, 1989), pois, nas gerações iniciais $\left(F_{2}, F_{3}\right.$ e $\left.F_{4}\right)$, a interação famílias $\mathrm{x}$ anos é significativa (CUTRIM et al., 1997), dificultando a seleção de caracteres quantitativos, como a produtividade de grãos. Para tanto, estimativas de coeficientes de correlação linear entre caracteres têm sido obtidas e utilizadas como estratégia de seleção indireta. Se o caráter sob seleção apresentar alta herdabilidade e coeficiente de correlação linear elevado com a produtividade de grãos, a seleção indireta será eficiente na identificação de genótipos superiores.

'Departamento de Fitotecnia, Centro de Ciências Rurais (CCR), Universidade Federal de Santa Maria (UFSM), 97105-900, Santa

Maria, RS, Brasil. E-mail: nerineia@hotmail.ufsm.br. *Autor para correspondência.

"Programa de Pós-graduação em Agronomia (PPGA), CCR, UFSM, Santa Maria, RS, Brasil.

${ }^{\mathrm{II}}$ Curso de Agronomia, CCR, UFSM, Santa Maria, RS, Brasil. 
Correlações positivas e de alta magnitude foram obtidas entre a produtividade de grãos e os componentes primários em feijão (KUREK et al., 2001; RIBEIRO et al., 2001; COELHO et al., 2002). Estimativas de correlação apresentam ampla possibilidade de utilização no melhoramento genético, principalmente para caracteres de difícil seleção, em razão das dificuldades de avaliação e de identificação ou da baixa herdabilidade (CARVALHO et al., 2004).

A nota geral de adaptação (NG), atribuída com base em uma escala de notas que varia de 1 (excelente) a 9 (péssimo), tem sido utilizada em gerações avançadas (linhas endogâmicas) para descartar linhagens nitidamente inferiores nos ensaios de valor de cultivo e uso (VCU). Isso porque a nota geral de adaptação consiste de uma avaliação visual, que dispensa a contagem do número de vagens por planta e sementes por vagem e a determinação da massa de 100 grãos e considera também a arquitetura das plantas e a ocorrência de sintomas de doenças nas vagens. Portanto, é uma medida de fácil e de rápida determinação, que pode ser incorporada na rotina do programa de melhoramento. No entanto, há dúvidas se a nota geral de adaptação pode ser utilizada em gerações precoces, para o descarte de progênies inferiores antes da colheita, como estratégia de seleção indireta para maior produtividade de grãos. Por isso, o objetivo deste trabalho foi avaliar a associação entre a nota geral de adaptação e a produtividade de grãos de feijão, como critério para a seleção indireta de genótipos com alto potencial produtivo.

Nove experimentos foram conduzidos no Departamento de Fitotecnia da Universidade Federal de Santa Maria, em Santa Maria, Rio Grande do Sul (latitude $29^{\circ} 42 \mathrm{~S}$, longitude $53^{\circ} 49 \mathrm{~W}$ e $95 \mathrm{~m}$ de altitude), nos anos agrícolas 2000/2001, 2001/2002, 2002/2003, 2003/2004 e 2004/2005, em duas épocas de cultivo: safra, com semeadura em setembro ou outubro, e safrinha, com semeadura em janeiro ou fevereiro. Foram avaliadas 14 cultivares de feijão ('Carioca', 'Diamante Negro', 'TPS Nobre’, 'Guapo Brilhante’, 'Guateian 6662', 'IAPAR 44', 'Iraí’, 'Macanudo', 'Macotaço', 'Minuano', 'Pérola', 'Rio Tibagi', 'TPS Bionobre’ e ‘TPS Bonito') em delineamento de blocos casualizados, com três repetições. As parcelas foram constituídas de quatro linhas de $4 \mathrm{~m}$ de comprimento, espaçadas de 0,50m, e a área útil foi de $3 \mathrm{~m}^{2}$. A densidade de semeadura foi ajustada de acordo com o hábito de crescimento de cada cultivar (CEPEF, 2003).
O solo foi preparado de maneira convencional, e a adubação foi realizada de acordo com a interpretação da análise química do solo. O controle de insetos foi efetuado com a aplicação de Metamidofós, e o controle de plantas invasoras foi realizado manualmente, sempre que necessário, de modo que a cultura não sofresse competição. O controle de doenças não foi realizado.

A nota geral de adaptação foi determinada na maturação por meio de uma escala de notas, variando de 1 a 9, em que a nota 1 refere-se à planta ereta, com uma haste, maior número de vagens por planta e ausência de sintomas de doenças em vagens; 2 - planta ereta, com uma guia curta, menor número de vagens e mais sintomas de doenças em vagens do que observado em 1; 3 - planta ereta, com algumas ramificações, menor número de vagens e mais sintomas de doenças em vagens do que observado em 2; 4 - planta ereta, com algumas guias longas, menor número de vagens e mais sintomas de doenças em vagens do que observado em 3; 5 - planta ereta, com muitas ramificações e tendência à prostrada, menor número de vagens e mais sintomas de doenças em vagens do que observado em 4; 6 planta semiereta, pouco prostrada, menor número de vagens e mais sintomas de doenças em vagens do que observado em 5; 7 - planta semiereta, medianamente prostrada, menor número de vagens e mais sintomas de doenças em vagens do que observado em 6; 8 planta prostrada, menor número de vagens e mais sintomas de doenças em vagens do que observado em 7; e 9 - planta com internódios longos, muito prostrada, menor número de vagens por planta e alta severidade de sintomas de doenças em vagens.

As doenças avaliadas nas vagens foram antracnose (Colletotrichum lindemuthianum), crestamento bacteriano (Xanthomonas campestris pv. phaseoli) e ferrugem (Uromyces appendiculatus), por meio de observação visual com atribuição de notas. Para as duas primeiras, as seguintes notas foram atribuídas: 1 - ausência de lesões; 3 - até 1\% das vagens com lesões; 5 - 1 a 5\% das vagens com lesões; 7 - 5 a $20 \%$ das vagens com lesões; e 9 - mais de $20 \%$ das vagens com lesões. Para a ferrugem, foram usadas notas variando de 1 - ausência de infecção; 2 - 1\% de infecção; 3 - 5\% de infecção; 4 - 10 \% de infecção; 5 - 20\% de infecção; 6 - 40\% de infecção; 7 - 60\% de infecção; 8 80\% de infecção; e 9 - 100\% de infecção. Para tanto, as plantas da área útil foram avaliadas visualmente por três selecionadores com experiência com a cultura. 
A colheita e a trilha das plantas foram realizadas manualmente na maturação. Após a retirada das impurezas, os grãos foram secados em estufa, a $65^{\circ} \mathrm{C}$, até umidade de $13 \%$, quando se quantificou a produtividade média de grãos ( $\left(\mathrm{m} 3 \mathrm{~m}^{2}\right.$ ) e o valor obtido foi transformado para $\mathrm{kg} \mathrm{ha}^{-1}$.

A análise de correlação linear de Pearson foi realizada entre a nota geral de adaptação e a produtividade de grãos, em cada experimento, com base em 42 observações (14 cultivares x três repetições) e no geral a partir de 378 observações (nove experimentos x 14 cultivares $x$ três repetições). A significância do coeficiente de correlação linear foi verificada por meio do teste $\mathrm{t}$ de Student. O diagrama de dispersão das notas gerais de adaptação e da produtividade de grãos foi apresentado para cada ambiente (experimento).

A produtividade média de grãos foi superior nos ambientes de safra (1 983 $\mathrm{kg} \mathrm{ha}^{-1}$ ), ou seja, quando a semeadura foi realizada nos meses de setembro ou de outubro (Tabela 1). Como nessa época de cultivo as condições metereológicas foram mais favoráveis ao desenvolvimento das plantas de feijão, foram observados os menores valores para as notas gerais de adaptação (melhor adaptação). Nos ambientes de safrinha, a produtividade média foi baixa $\left(694 \mathrm{~kg} \mathrm{ha}^{-1}\right)$. Isso porque a colheita coincidiu com o período de temperaturas mínimas mais baixas e de alta quantidade de precipitação pluvial, que é constatado no outono, na região da Depressão Central do Rio Grande do Sul. Nessas condições, os selecionadores atribuíram maiores notas gerais de adaptação (adaptação inferior),

Tabela 1 - Médias da nota geral de adaptação e da produtividade de grãos de feijão em cada ambiente.

\begin{tabular}{|c|c|c|}
\hline Ambiente & Nota geral $^{(1)}$ & $\begin{array}{l}\text { Produtividade de } \\
\text { grãos }\left(\mathrm{kg} \mathrm{ha}^{-1}\right)\end{array}$ \\
\hline Safra 2000/2001 & 5,071 & 1794 \\
\hline Safrinha 2001 & 6,143 & 888 \\
\hline Safra 2001/2002 & 3,500 & 2336 \\
\hline Safrinha 2002 & 6,000 & 741 \\
\hline Safra 2002/2003 & 5,714 & 1872 \\
\hline Safrinha 2003 & 6,905 & 264 \\
\hline Safra 2003/2004 & 5,214 & 1966 \\
\hline Safrinha 2004 & 6,548 & 882 \\
\hline Safra $2004 / 2005$ & 4,786 & 1947 \\
\hline Média geral & 5,542 & 1410 \\
\hline Média das safras & 4,857 & 1983 \\
\hline Média das safrinhas & 6,399 & 694 \\
\hline
\end{tabular}

\footnotetext{
${ }^{(1)}$ Escala de notas que varia de 1 (excelente) a 9 (péssimo).
}

pois as plantas apresentaram maior acamamento, menor número de vagens por planta e alta ocorrência de doenças.

Os coeficientes de correlação linear de Pearson foram negativos em todos os ambientes, variando de -0,3363 (safra 2000/2001) a -0,6053 (safrinha 2003) (Figura 1), e de magnitude média, de acordo com a classificação apresentada por CARVALHO et al. (2004). Com base em todas as observações ( $n=378)$, o coeficiente de correlação linear foi de -0,6134. Assim, a produtividade de grãos foi maior nos genótipos que apresentaram menor nota geral de adaptação (maior adaptação). Isso porque valores próximos a um, na escala de avaliação, caracterizam plantas com arquitetura ereta, maior número de vagens por planta e ausência de sintomas de doenças em vagens.

Nos diagramas de dispersão, se verificou que, nos cultivos de safra, a maior concentração de pontos ocorreu nas notas gerais de adaptação mais baixas e nos maiores valores de produtividade média. Assim, em ambientes favoráveis (safra), foi possível a expressão genética do alto potencial de produtividade das cultivares avaliadas, diferentemente do que foi observado nos ambientes desfavoráveis (safrinha). Portanto, o emprego da seleção indireta será diretamente dependente dos efeitos do ambiente, como constatado em aveia (CAIERÃO et al., 2006).

Considerando que a avaliação visual da nota geral de adaptação é de fácil mensuração e correlacionada com a produtividade de grãos, conforme observado nos ensaios de valor de cultivo e uso, é de se esperar que, em gerações precoces, apresente eficiência para o descarte de progênies nitidamente inferiores, antes da colheita. Entretanto, como a seleção precoce em feijão apresentou baixa eficiência (HAMBLIN \& EVANS, 1976; PATIÑO \& SINGH, 1989), o emprego da nota geral de adaptação deverá ser avaliado nas etapas iniciais do programa de melhoramento, quando é alta a interação famílias x anos (CUTRIM et al., 1997). Se a nota geral de adaptação apresentar alta associação com a produtividade de grãos em gerações precoces, esta poderá ser útil também, em trabalhos de seleção indireta que visam à melhoria da produtividade de grãos em feijão. Isto porque a nota geral de adaptação apresenta associação linear com a produtividade de grãos de feijão, podendo ser utilizada com eficiência na seleção de linhas endogâmicas mais produtivas.

\section{AGRADECIMENTOS}

Ao Conselho Nacional de Desenvolvimento Científico e Tecnológico (CNPq) e à Fundação de Amparo à Pesquisa do Estado do Rio Grande do Sul (FAPERGS), pelas bolsas concedidas.

Ciência Rural, v.40, n.4, abr, 2010. 


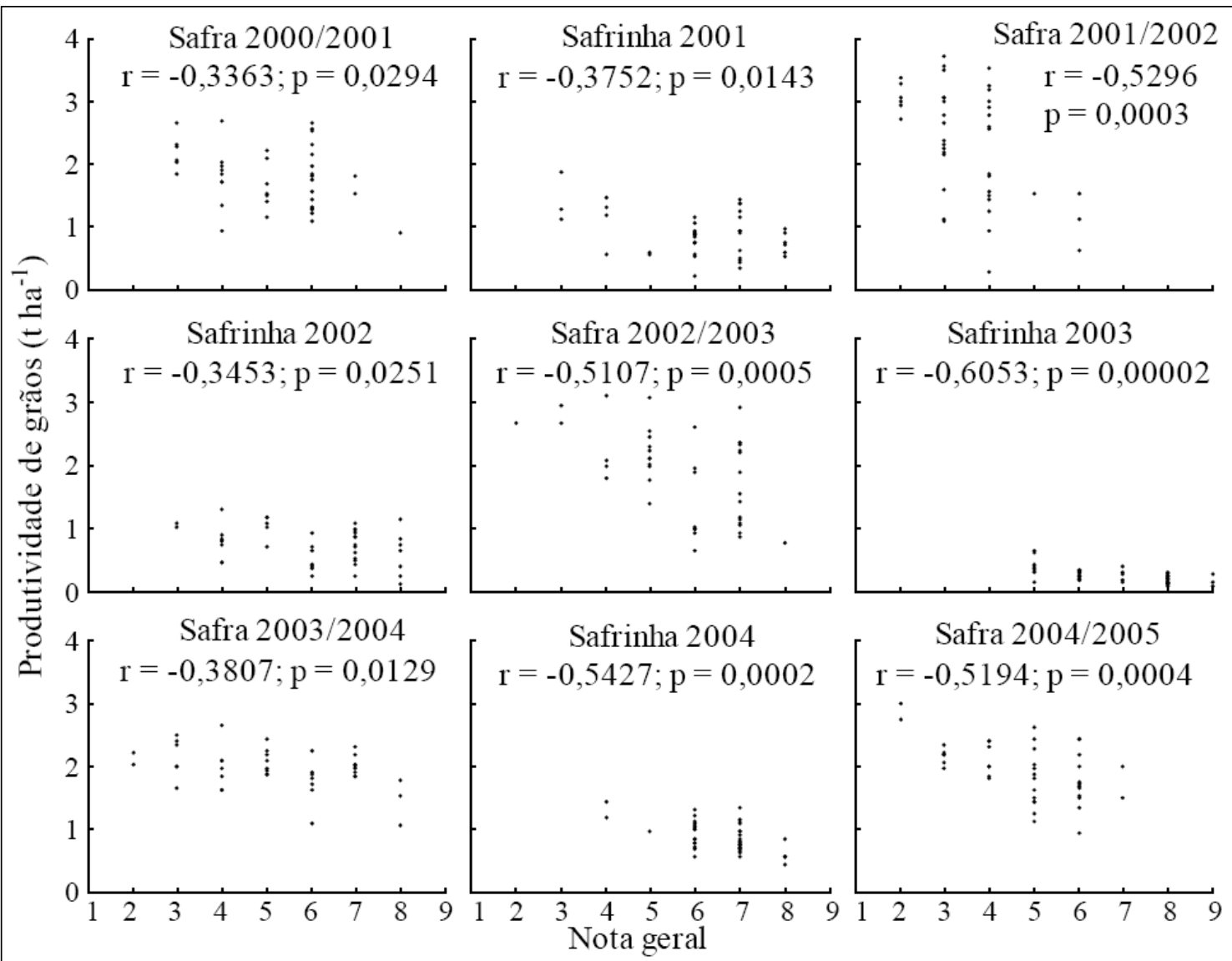

Figura 1 - Diagrama de dispersão entre a nota geral de adaptação e a produtividade de grãos, coeficiente de correlação linear de Pearson (r) e nível mínimo de significância (P) de 14 cultivares de feijão avaliadas em nove ambientes.

\section{REFERÊNCIAS}

CAIERÃO, E. et al. Seleção indireta para o incremento do rendimento de grãos em aveia. Ciência Rural, v.36, p.11261131, 2006. Disponível em: <http://www.scielo.br/ s c i e lo.ph p ? s c ript = s ci_art text \& pid = S 0103 84782006000400013\&lng=pt\&nrm=iso $>$. Acesso em: 24 ago. 2009. doi: 10.1590/S0103-84782006000400013.

CARVALHO, F.I.F. et al. Estimativas e implicações da correlação no melhoramento vegetal. Pelotas: UFPEL, 2004. 142p.

CEPEF. Comissão Estadual de Pesquisa de Feijão. Indicações técnicas para a cultura do feijão no Rio Grande do Sul 2003/04. Passo Fundo: UPF, 2003. 149p.

COELHO, A.D.F. et al. Herdabilidades e correlações da produção do feijão e dos seus componentes primários, nas épocas de cultivo da primavera-verão e do verão-outono. Ciência Rural, v.32, p.211-216, 2002. Disponível em: <http://www.scielo.br/ s c i elo.php ? s cript = s ci__art text \& pid = S 0103 $84782002000200005 \& \operatorname{lng}=p t \& n r m=i s o>$. Acesso em 24 ago. 2009. doi: 10.1590/S0103-84782002000200005.
CUTRIM, V.A. et al. Eficiência da seleção visual na produtividade de arroz (Oryza sativa L.) irrigado. Pesquisa Agropecuária Brasileira, v.32, p 601-606, 1997.

HAMBLIN, J.; EVANS, A.M. The estimation of cross yield using early generation and parental yields in dry beans (Phaseolus vulgaris L.). Euphytica, v.25, p.515-520, 1976.

KUREK, A. et al. Análise de trilha como critério de seleção indireta para rendimento de grãos em feijão. Revista Brasileira de Agrociência, v.7, p.29-32, 2001.

PATIÑO, H.; SINGH, S.P. Visual selection for seed yield in the $\mathrm{F}_{2}$ and $\mathrm{F}_{3}$ generation of nine common bean crosses. Annual Report Bean Improvement Cooperative, v.32, p.79-80, 1989.

RIBEIRO, N.D. et al. Correlações genéticas de caracteres agromorfológicos e suas implicações na seleção de genótipos de feijão preto. Revista Científica Rural, v.6, p.168-176, 2001.

RIBEIRO, N.D. et al. Genetic progress in traits of yield, phenology and morphology of common bean. Crop Breeding and Applied Biotecnology, v.8, p.236-242, 2008. 